https://doi.org/10.5719/aub-g/69.1/2

\title{
NOUVELLE PERSPECTIVE POUR LA CARTOGRAPHIE DE LA DYNAMIQUE RECENTE DES PAYSAGES AGRAIRES: APPLICATION AUX CULTURES MARAICHERES ET FOURRAGERES DU PPI DE BORJ TOUMI (NORD-EST DE LA TUNISIE)
}

\author{
HAMOUDA SAMAALI ${ }^{1}$
}

\begin{abstract}
This paper aims to map the evolution of land cover and land use in Borj Toumi's PPI for the period 2015-2019 (from May to July). The study examines the aptitudes of irrigation water use in the new environment characterized by "demand management" and its impact on management mode. The methodological approach is inspired by a new cartographic vision based on the use of Sentinel 2A and Landsat 8 / OLI images. The monitoring (intra-annual and inter-annual) and estimation of irrigated plots (vegetable and fodder crops) is based on the calculation and cross-referencing of indicators (NDVI and NDWI) from multi-sensor images. The cartographic and statistical results show that the areas dedicated to market gardening and fodder crops are estimated at nearly 300 hectares for the month of May (2015 and 2016). However, a decline of around 50\% is recorded during the month of July (same period). In addition, an average regression rate of around $163.9 \%$ for Sentinel images and $124.42 \%$ for Landsat images is recorded for the period 2017-2018. A slight increase in irrigated areas is observed for 2019 (watered year). Several factors are behind these fluctuations. However, the weighting factor lies in the application of a specific irrigation water management plan, which manifests itself in the distribution of only $20 \%$ of the usual volumes during drought phases.
\end{abstract}

Keywords: Mapping, Successions of irrigated crops, Optical multi-sensor remote sensing, Irrigation water management, Borj Toumi PPI.

1 Enseignant chercheur, Faculté des Sciences Humaines et Sociales de Tunis, département de Géographie. Laboratoire: Géomatique des géosystèmes (Géomag), Faculté des Lettres, des Arts et des Humanités, Campus Universitaire, La Manouba, 2010. Mail : samaalihamouda@yahoo.fr 


\section{Introduction}

Grace au projet national de la "réforme agraire », le paysage agricole dans le secteur de Borj Toumi a connu un véritable bouleversement et ce depuis les années "1960". Ce changement se traduit par des modifications dans les pratiques culturales. L'Office de Mise en Valeur de la Vallée de Mejerda (OMVVM) est à l'origine de ce réaménagement des sociétés rurales. Il a en effet, tenté d'assurer une meilleure distribution des terres, à des paysans démunis, dans le but de les reconvertir en cultures irriguées intensives. Le choix de l'étude des territoires irrigués se justifie par l'importance accordée à ce secteur en tant que pilier de l'économie nationale. En effet, cette activité agricole présente d'importants enjeux environnementaux (dégradation et érosion des sols, forte consommation des ressources en eau,...) et socio-économiques (rentabilité, valeurs ajoutées à l'économie familiale, incertitude économique, techniques de gestion, spéculation financière,...). En outre, elle renseigne sur les attitudes et les pratiques culturales ainsi que sur la performance des modèles de gouvernance et les modes de gestion des ressources en eau.

Après une première phase de "grande hydraulique » qui encourage l'irrigation (gestion de l'offre), durant laquelle la Tunisie indépendante s'est investie dans la mobilisation des ressources via la réalisation des grands barrages, la nouvelle politique hydraulique, débutée depuis trois décennies, s'est orientée vers "la gestion de la demande". Dans ce cadre, une réforme a été établie au niveau institutionnel et les subventions préférentielles octroyées par l'Etat à l'utilisation de l'eau d'irrigation ont été révisées. Ces changements ont engendré un certain boycotte des cultures consommatrices de l'eau, notamment, celles maraîchères et fourragères. C'est dans ce contexte que notre contribution vise à cerner l'impact des nouvelles orientations dans la politique hydraulique agricole sur la nature et le rythme des pratiques culturales. Le secteur de Borj Toumi présente un site favorable à cette l'étude puisqu'il a subit les effets à la fois de la réforme agraire et des politiques récentes liées à la gestion de l'eau d'irrigation en Tunisie.

L'étude présente une nouvelle vision cartographique basée sur l'utilisation des données spatiales. A ce propos, il s'agit de voir dans quelle mesure, les données satellitaires multi-capteurs peuvent contribuer à 
caractériser et suivre l'occupation du sol à l'échelle de la parcelle ? Examiner le potentiel de l'utilisation de l'eau d'irrigation dans la nouvelle conjoncture de gestion et en dépend des allocations disponibles? Ce travail s'appuie sur une approche méthodologique particulière basée sur des indicateurs et sur le couplage d'images issues de différents capteurs à très haute résolution spatiale (THRS). A cet égard, plusieurs satellites offrent une base d'images gratuites aux utilisateurs et la résolution spatiale des scènes fournies répondent au mieux à la cartographie parcellaire.

La cartographie de la dynamique récente des exploitations agricoles occupées par des cultures maraichères et fourragères se base sur l'utilisation des scènes Landsat8/OLI et Sentinel, niveau 2A et s'intéresse à la période estivale (mai-juillet) de 2015 à 2019. Tout de même, une enquête socio-économique est opérée auprès des agriculteurs de Borj Toumi afin d'optimiser cette recherche et de mettre en œuvre un diagnostic local sur l'état de la gestion et de l'occupation du sol.

\section{Le contexte de l'étude}

\section{1) Aperçu historique sur la gestion de l'eau d'irrigation en Tunisie}

Les agriculteurs des périmètres irrigués ont bénéficié pour une longue période des subventions de l'eau et ont payé des tarifs très faibles. Ceci, fait partie dans une politique qui encourage la production afin de garantir la sécurité alimentaire et faire face à l'exode rural (Belhedi A., 2017). Les grands aménagements hydrauliques animés par l'Etat depuis l'indépendance ont servi de base pour assurer une stratégie qui encourage l'irrigation (Samaâli H., 2019). Cette première phase qui s'étend jusqu'à la fin des années « 1980 » est caractérisée par une gestion communautaire. L'état s'est chargé des grands aménagements et de la gestion de l'eau d'irrigation au moyen des 13 offices de mise en valeur. Les superficies des cultures en irrigués ont alors cru d'une façon remarquable notamment, durant la décennie 1980-1990 (Fig. 1). Avec un taux d'accroissement de l'ordre de 19 \% (même période), le secteur privé détient la superficie majoritaire des exploitations agricoles en intensifs. 


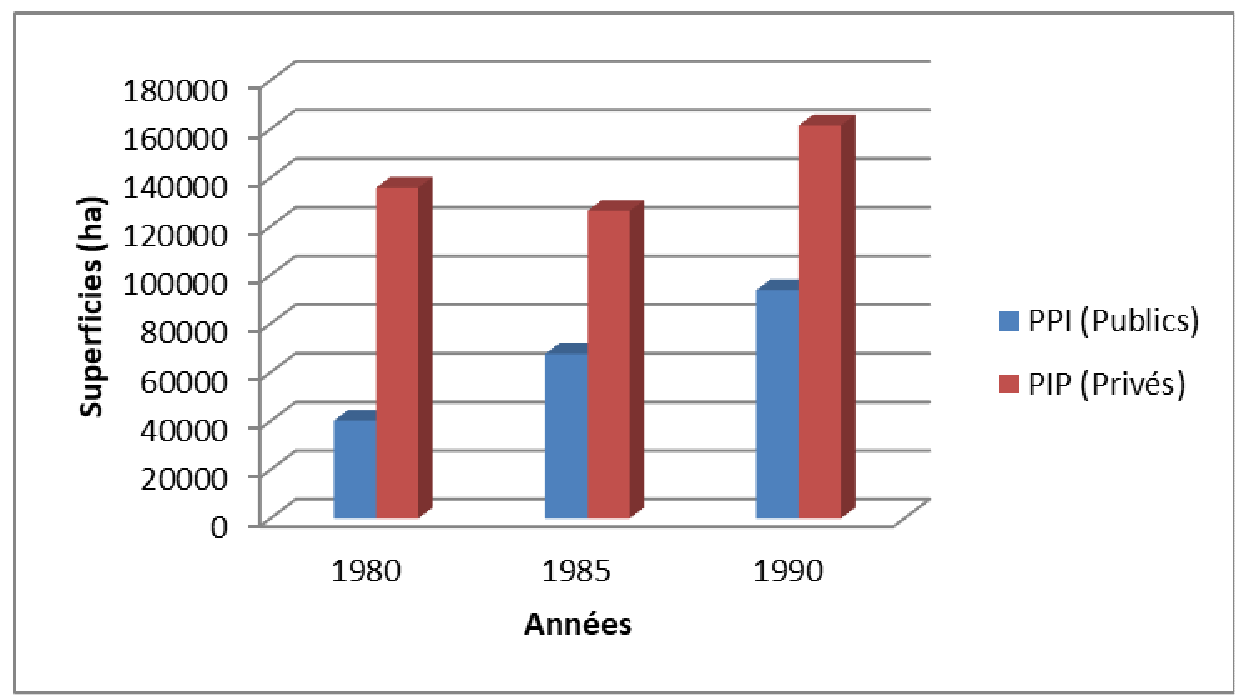

Fig.1. Evolution de la superficie des périmètres irrigués publics et privés en Tunisie entre 1980 et 1990 (Ben Hamouda N, 1999)

A partir des années « 1990 », les anciennes orientations de l'Etat sont immédiatement changées. L'eau est devenue une ressource rare (Nasr J., 2015) et les efforts de mobilisation ont atteint un seuil de saturation. Par conséquent, la nouvelle politique de l'Etat vise une meilleure gestion de l'eau d'irrigation. Dans le cadre de l'application du Plan d'Ajustement Structurel Agricole (PASA), les subventions faites par l'Etat ont été réduites graduellement et ne présentent plus qu'un faible part des allocations de l'eau d'irrigation (Hanafi S., 2011). En revanche, l'Etat tunisien s'est investi dans des programmes d'économie d'eau. En effet, en 1995, le Ministère de l'Agriculture et des Ressources Hydrauliques « a mis en œuvre le Programme National d'Economie d'Eau en Irrigation (PNEEI) qui subventionne les équipements économes en eau d'irrigation (localisée, aspersion et gravitaire améliorée) et concerne maintenant 80\% des superficies irriguées »(AFD, 2008). Dans la même optique, d'autres programmes d'économie d'eau ont été lancé (INECO, Projet d'Investissement dans le Secteur de l'Eau PISEAU I et II, économie d'eau 2000, stratégie Eau 2050...). L'objectif était de conserver et d'assurer une meilleure gestion de cette ressource, d'agir par une réforme au niveau des tarifications et de renforcer les législatives de décentralisation. Ce 
dernier point, touche à la réforme du cadre institutionnel dans le sens de confier la gestion des PPI à des Associations d'Intérêt Collectif (AIC) et qui se sont évoluent ensuite en Groupements de Développement Agricole (GDA). Ce changement est vécu comme un « désengagement total » de l'Etat de la gestion des périmètres irrigués. Le contexte actuel des GDAs, dénonce un certain déclin et disfonctionnement. Dans ce contexte, le rapport national du secteur de l'eau (www.onagri.nat.tn) affirme qu'en 2017, 56 \% des Groupement de Développement Agricole sont considérés comme non-actifs. Ils se heurtent à des problèmes divers tels que :

- Manque d'autonomie.

- Des agriculteurs qui dénoncent des abus de gestion interne au sein des groupements.

- Non-paiement des redevances hydrauliques.

- Endettements envers la Société Tunisienne d'Electricité et du Gaz (STEG).

- Des agriculteurs qui changent leurs attitudes culturales et boycottent certaines cultures jugées très consommatrices de la ressource en eau.

\section{2) Cadre géographique de la zone d'étude}

Le périmètre d'étude se localise dans l'extrémité ouest du Grand Tunis, entre les longitudes $9,43^{\circ}$ et $9,46 \mathrm{E}$ et les latitudes $36,45^{\circ}$ et $36,48^{\circ} \mathrm{N}$ (Fig. 2). Il constitue, une zone irriguée à caractère public, instaurée depuis 1966 dans le cadre du programme de réforme agraire animé par l'OMVVM. Le périmètre public de Borj Toumi PPI (Tongar), couvre une superficie de l'ordre de 926 ha est "s'étend sur une plaine alluviale située entre les monts Lansarine et les méandres de l'oued Majerda en amont du delta de Majerda » (Samaâli, H. et Mjejra, M., 2020). Le secteur d'étude présente des pentes faibles et des altitudes qui varient de $43 \mathrm{~m}$ à $57 \mathrm{~m}$ dans le sud (les environs d'oued Mejerda) et de $74 \mathrm{~m}$ à $96 \mathrm{~m}$ du côté nord (Jebel Lansarine). La pluviométrie moyenne de ce secteur est comprise entre 400 et $450 \mathrm{~mm} / \mathrm{an}$ alors que l'ETP de référence est d'environ 1120 mm/an (Hénia, L., 2008). 


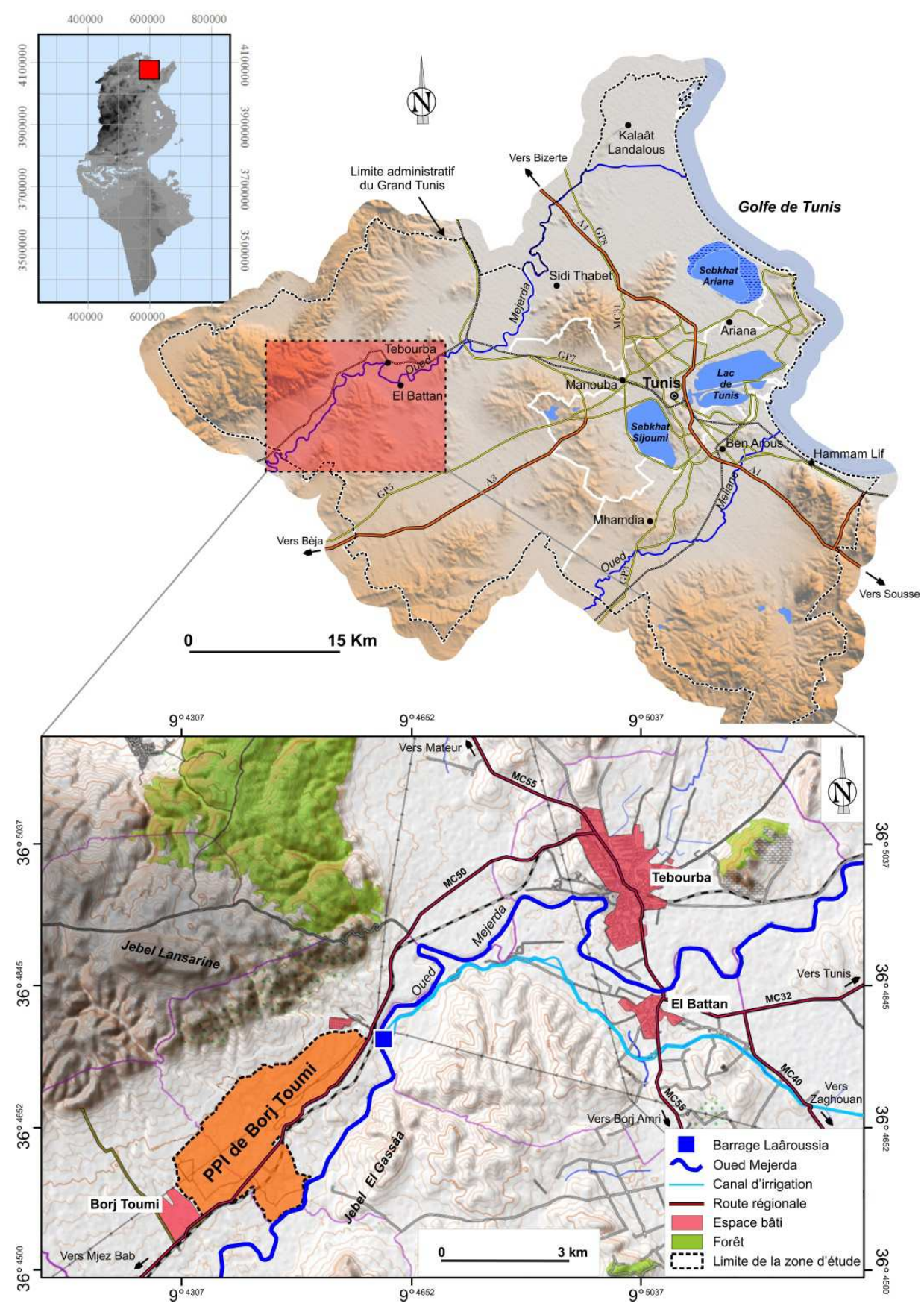

Fig. 2. Localisation et délimitation du secteur d'étude dans le Grand Tunis (image de fond : Global Mapper, Samaâli, H. et Mjejra, M., 2020 : carte améliorée) 
L'irrigation dans ce périmètre est assurée par des prises directes à partir de l'Oued Mejerda (en limitrophe) et par une station de pompage au niveau de barrage Laroussia (Fig. 2). L'irrigation dite "de surface" (gravitaire) domine les modes pratiqués pour une superficie nette de l'ordre de $425 \mathrm{ha}$, en second rang le mode d'irrigation "sous haute pression » (260 ha), ensuite celui « sous basse pression » (130) (Hanafi, S. et al., 2014). Le plan cadastral du PPI est dominé par des exploitations de faibles tailles (ne dépasse pas $7 \mathrm{ha}$ ), à l'exception d'un seul agriculteur et de deux sociétés de mise en valeur qui possèdent des exploitations varient de 80 ha à 180 ha (Hanafi, S. et al., 2014). Rappelons ici que ces exploitations agricoles sont mises en valeur pour pratiquer essentiellement, les cultures maraîchères, fourragères, l'arboriculture fruitière et avec des fréquences faibles pour les céréales.

\section{Une approche méthodologique particulière}

\section{1) Études antérieures sur la cartographie par télédétection des zones irriguées}

Des expériences récentes ont montré l'avantage et la performance de l'utilisation de la télédétection en tant qu'un outil privilégié pour l'étude des cultures irriguées. Nous citons, quelques études qui ont significativement orienté les choix des satellites et qui ont montré des résultats encourageants. Certes, l'étude de Toomanian, N. et al. (2004) a travers laquelle les auteurs ont exploré des séries temporelles d'images NOAA pour identifier, estimer et cartographier les superficies irriguées au niveau du bassin versant de "Zayandeh Rud" (Iran). Cette étude se base sur la comparaison des classifications supervisées effectuées aux images et s'appuie aussi sur l'indice de "potentiel irrigation efficace". Malgré la faible résolution des images utilisées $\left(1,1 \mathrm{~km}^{2}\right)$, leurs résultats ont montré un accroissement de la superficie irriguée entre 1995 et 1999.

Par ailleurs, l'étude faite par Velpuri, N. et al., (2009) et qui a démontré l'influence de la résolution spatiale des capteurs sur l'estimation des surfaces irriguées. Le travail est fondé sur l'utilisation d'une approche multi-capteurs issus de différents satellites, à savoir 
NOAA (AVHRR) avec une résolution de $1100 \mathrm{~m}$, TERRA (MODIS) avec une résolution spatiale de $500 \mathrm{~m}$ et de $250 \mathrm{~m}$ ainsi que le satellite LANDSAT $(\mathrm{ETM}+)$ avec une très haute résolution spatiale $(30 \mathrm{~m})$.

Dans ce même contexte, une autre étude a été réalisée par Traoré, F. et al., (2012) pour le bassin versant de Kou (Burkina Fasso). L'approche méthodologique suivie pour estimer les zones agricoles irriguées s'appuie sur l'utilisation des images Landsat à très haute résolution spatiale $(30 \mathrm{~m})$. Elle est basée sur la comparaison des classifications supervisée par maximum de vraisemblance ainsi que la comparaison des séries d'indices de végétation normalisé (NDVI). L'évaluation des résultats par la matrice de confusion ou par le coefficient Kappa a donnée des résultats encourageants.

L'étude faite par Lamhamedi, B.E. et al. (2017), repose aussi sur l'utilisation des images de type THRS (Landsat 8) afin d'extraire automatiquement les zones irriguées dans la région de Gharb (Maroc). L'approche méthodologique proposée, ici, s'appuie sur l'utilisation de trois paramètres :

- Classification par règles de décision sur les statistiques de l'NDVI annuel.

- Classification par règles de décision sur les températures et les différences des NDVI.

- Classification supervisée par méthode de «Plus Proche Voisin ».

En dépit de difficultés rencontrées (différence de taille des parcelles, différents états de cultures pratiquées,...), les résultats obtenus ont montré l'apport de cette nouvelle approche.

D'autres projets sont en cours notamment celui de «irriga-detection » coordonné par Samuel Corgne pour le site expérimental Berambadi en Inde (2017-2020). L'objectif principal de ce travail est la cartographie des cultures irriguées à une échelle parcellaire et à une échelle intra-annuelle à partir d'une série d'images radar et optique (sentinel-1 et sentinel-2) à haute résolution spatiale et temporelle (http://letg.cnrs.fr/auteur38.html).

Les expériences et les études faites à l'échelle internationale sont nombreuses et les approches suivies sont assez riches pour on déduire une approche particulière basée sur l'utilisation des indicateurs et sur le couplage d'images issues de différents capteurs afin de répondre à notre problématique. 


\section{2) Capteurs et indicateurs choisis}

Ce travail s'inscrit dans l'approche cartographique multi-sources pour caractériser et retracer l'occupation du sol et ses changements. La méthodologie adaptée pour suivre les campagnes agricoles s'appuie sur des indicateurs issus des images satellitaires multi-capteurs. L'estimation par télédétection des superficies irriguées selon une approche multi-échelles fait partie des objectifs primordiaux de ce travail. L'étude s'intéresse à la période de «2015-2019». Un choix technique s'explique par l'utilisation des nouvelles images optiques améliorées des satellites Sentinel, niveau $2 \mathrm{~A}$ et Landsat 8/OLI (tableau 1). Ce choix temporel vise, sans doute, à mieux cadrer les rotations agricoles exercées dans le PPI de Borj Toumi.

Tableau 1

Les caractéristiques des images satellitaires utilisées

\begin{tabular}{|c|c|c|c|c|c|}
\hline & Satellite & $\begin{array}{c}\text { Date } \\
\text { d'acquisition }\end{array}$ & $\begin{array}{c}\text { Bandes } \\
\text { utilisées }\end{array}$ & $\begin{array}{l}\text { Résolution } \\
\text { finale }\end{array}$ & Nébulosité \\
\hline \multirow{2}{*}{$\begin{array}{l}\text { Mai } \\
2015\end{array}$} & Sentinel 2A & 11-05-2015 & $4-8-8 a-11$ & $10 \mathrm{~m} / 20 \mathrm{~m}$ & Faible \\
\hline & $\begin{array}{c}\text { Landsat 8/ } \\
\text { OLI }\end{array}$ & 14-05-2015 & $4-5-7-(8)$ & $15 \mathrm{~m}$ & Faible \\
\hline \multirow{2}{*}{$\begin{array}{c}\text { Juillet } \\
2015\end{array}$} & Sentinel 2A & 09-07-2015 & 4-8-8a-11 & $10 \mathrm{~m} / 20 \mathrm{~m}$ & Faible \\
\hline & $\begin{array}{l}\text { Landsat 8/ } \\
\text { OLI }\end{array}$ & 01-07-2015 & $4-5-7-(8)$ & $15 \mathrm{~m}$ & Faible \\
\hline \multirow{2}{*}{$\begin{array}{l}\text { Mai } \\
2016\end{array}$} & Sentinel 2A & $12-05-2016$ & 4-8-8a-11 & $10 \mathrm{~m} / 20 \mathrm{~m}$ & Faible \\
\hline & $\begin{array}{c}\text { Landsat 8/ } \\
\text { OLI }\end{array}$ & 16-05-2016 & $4-5-7-(8)$ & $15 \mathrm{~m}$ & Faible \\
\hline \multirow{2}{*}{$\begin{array}{l}\text { Juillet } \\
2016\end{array}$} & Sentinel 2A & $17-07-2016$ & $4-8-8 a-11$ & $10 \mathrm{~m} / 20 \mathrm{~m}$ & Faible \\
\hline & $\begin{array}{c}\text { Landsat 8/ } \\
\text { OLI }\end{array}$ & 19-07-2016 & $4-5-7-(8)$ & $15 \mathrm{~m}$ & Faible \\
\hline \multirow{2}{*}{$\begin{array}{l}\text { Mai } \\
2017\end{array}$} & Sentinel 2A & 04-05-2017 & $4-8-8 a-11$ & $10 \mathrm{~m} / 20 \mathrm{~m}$ & Faible \\
\hline & $\begin{array}{l}\text { Landsat 8/ } \\
\text { OLI }\end{array}$ & 03-05-2017 & $4-5-7-(8)$ & $15 \mathrm{~m}$ & Faible \\
\hline \multirow{2}{*}{$\begin{array}{c}\text { Juillet } \\
2017\end{array}$} & Sentinel 2A & 22-07-2017 & 4-8-8a-11 & $10 \mathrm{~m} / 20 \mathrm{~m}$ & Faible \\
\hline & $\begin{array}{c}\text { Landsat 8/ } \\
\text { OLI }\end{array}$ & 29-07-2017 & $4-5-7-(8)$ & $15 \mathrm{~m}$ & Faible \\
\hline \multirow{2}{*}{$\begin{array}{l}\text { Mai } \\
2018\end{array}$} & Sentinel 2A & 22-05-2018 & 4-8-8a-11 & $10 \mathrm{~m} / 20 \mathrm{~m}$ & Faible \\
\hline & $\begin{array}{c}\text { Landsat 8/ } \\
\text { OLI }\end{array}$ & $16-05-2018$ & $4-5-7-(8)$ & $15 \mathrm{~m}$ & Faible \\
\hline
\end{tabular}




\begin{tabular}{|c|c|c|c|c|c|}
\hline \multirow{2}{*}{$\begin{array}{l}\text { Juillet } \\
2018\end{array}$} & Sentinel 2A & 13-07-2018 & $4-8-8 a-11$ & $10 \mathrm{~m} / 20 \mathrm{~m}$ & Faible \\
\hline & $\begin{array}{c}\text { Landsat 8/ } \\
\text { OLI }\end{array}$ & 06-07-2018 & $4-5-7-(8)$ & $15 \mathrm{~m}$ & Faible \\
\hline \multirow{2}{*}{$\begin{array}{l}\text { Mai } \\
2019\end{array}$} & Sentinel 2A & 17-05-2019 & $4-8-8 a-11$ & $10 \mathrm{~m} / 20 \mathrm{~m}$ & Faible \\
\hline & $\begin{array}{c}\text { Landsat 8/ } \\
\text { OLI }\end{array}$ & $12-05-2019$ & $4-5-7-(8)$ & $15 \mathrm{~m}$ & Faible \\
\hline \multirow{2}{*}{$\begin{array}{l}\text { Juillet } \\
2019\end{array}$} & Sentinel 2A & 22-07-2019 & $4-8-8 a-11$ & $10 \mathrm{~m} / 20 \mathrm{~m}$ & Faible \\
\hline & $\begin{array}{c}\text { Landsat 8/ } \\
\text { OLI }\end{array}$ & $16-07-2019$ & $4-5-7-(8)$ & $15 \mathrm{~m}$ & Faible \\
\hline
\end{tabular}

(Source: Https://Www.Usgs.Gov/)

L'impact et l'effet des nuages sur les longueurs d'ondes du visible et $\mathrm{du}$ proche infrarouge (optique), expliquent le recours à la période estivale (mai et juillet pour les images). En même temps, c'est au cours de cette période que l'irrigation est fictive notamment pour les cultures maraichères de la saison et les cultures fourragères (Fig. 3). Le choix de cette période est justifié encore par «l'indice cultural» ou «le coefficient cultural (Kc)» en tant qu'un indicateur sur le rendement et les besoins d'eau de la plante tout au long de la phase de croissance (Fig. 3). Ainsi, les valeurs les plus élevées du Kc pour les quelques spéculations présentés (sauf pour l'olivier, qui supporte le stress hydrique) sont observées pendant la période de stress hydrique en Tunisie. La croissance de ces variétés cultivées est assurée donc par l'irrigation.

Des opérations de recalage spatial (sous le référentiel spatial UTM, Carthage-zone 32 Nord) et d'extraction de la zone d'étude sont effectuées aux images sous le logiciel de SIG ArGis 10.3®. Dans l'objectif de trouver une base commune pour la comparaison des scènes, toutes les images sont converties en réflectance (Chander et al., 2003, 2009 in Traoré, F. et al., 2012). Cette calibration est effectuée sous l'environnement Envi 5.3 grâce aux nouvelles fonctionnalités présentées (Jaziri, B., 2020). Afin de redéfinir la résolution spatiale des pixels, des opérations de "pancharping" ont été effectués aux images Landsat 8/ OLI (Fig. 4). Cette opération consiste à redimensionner les pixels en passant de $30 \mathrm{~m}$ à $15 \mathrm{~m}$ grâce à la huitième bande spectrale qui se situe dans la région spectrale « visible » $(0.503 \mu \mathrm{m}-0.676 \mu \mathrm{m})$. 


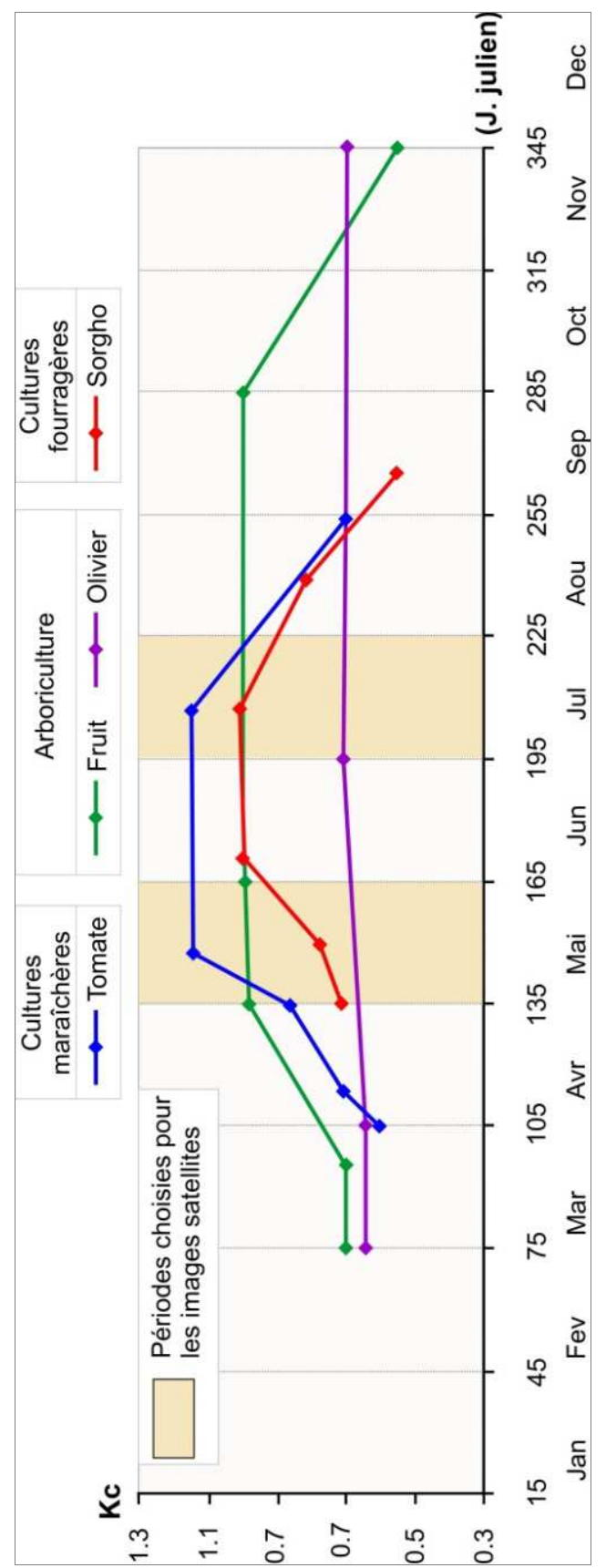

Fig. 3. Coefficients culturaux $(\mathrm{Kc})$ de quelques spéculations cultivées dans le PPI de Borj Toumi (Allen, R.G. et al., 1998 ; CRDA de la Manouba 2018 et enquête personnelle) 
La lecture de la dynamique des parcellaires agricoles s'est faite par une approche qui s'appuie sur l'utilisation de deux paramètres :

$>$ Classification par règles de décision sur les statistiques de l'indice NDVI (Normalized Difference Vegetation Index) qui permet de mettre en exergue la végétation pour les périodes retenues (mai et juillet). Différemment à l'arboriculture qui se caractérise par un effet de retardement dans la réponse de l'activité photosynthétique (Jaziri B. et al., 2018), les cultures fourragères et maraîchères ont une réponse presque immédiate (augmentation des valeurs de l'NDVI) en cas d'irrigation. L'indice de végétation se calcul selon l'équation suivante :

$$
\text { NDVI = (PIR-R)/ (PIR+R) soit, (B5-B4)/ (B5+B4) }
$$

(En cas d'images Landsat8/ OLI)

$$
\text { NDVI = (PIR-R)/ (PIR+R) soit, (B8-B4)/ (B8+B4) }
$$

Avec,

(En cas d'images Sentinel/2A)

PIR : Bande proche infrarouge.

$R$ : Bande rouge.

L'indice de végétation varie entre "1" (végétation en pleine activité chlorophyllienne) et "-1" (autres types d'occupation du sol). Généralement, les valeurs qui sont $>\mathbf{0 . 1}$, indiquent la présence d'une végétation plus au moins dense, alors que les valeurs $<0$, témoignent sur l'absence de végétation ou sur la présence de l'eau. D'après White (1996, in Traoré, F. et al., 2012), "une discrimination peut être faite entre végétation naturelle et cultures en utilisant une limite inférieure de NDVI de l'ordre de $\mathbf{0 . 4}$, qui sépare le groupe des herbes et arbustes du groupe des cultures ».

Le calcul de l'NDVI est effectué sous le logiciel Arc Gis. Ce dernier affiche les résultats sous format raster avec des valeurs groupées par classes. Afin de faire une discrimination entre les zones « végétatives » et celles «non végétatives », une reclassification (basée sur une reconnaissance 
automatique par le logiciel) a été opérée aux valeurs de l'NDVI. Ainsi, le raster obtenu se présente en deux plages :

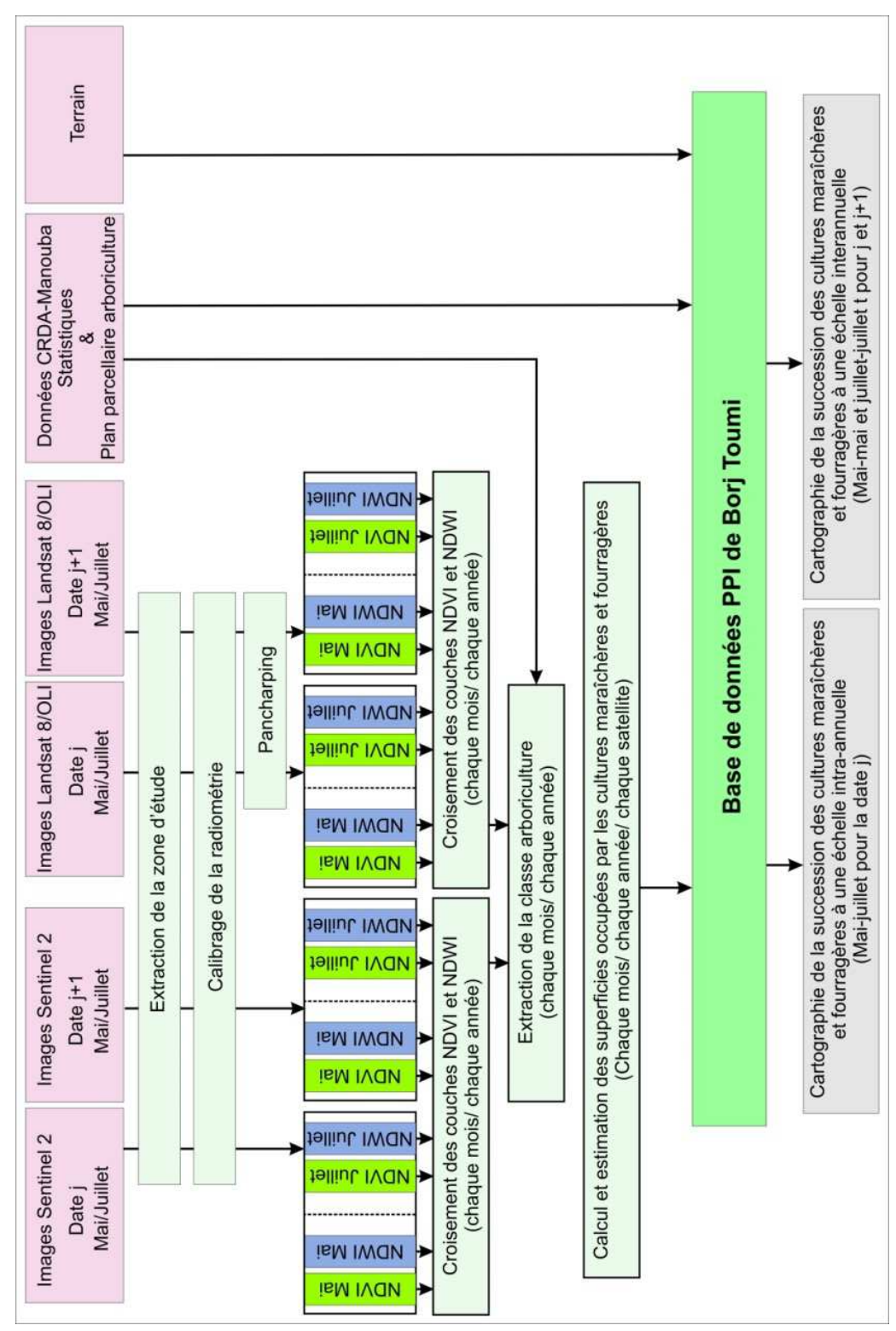

Fig. 4. Approche méthodologique utilisée pour l'étude de la succession des cultures maraichères et fourragères à une échelle intra-annuelle et interannuelle entre 2015 et 2019 dans le PPI de Borj Toumi 
- Une première, pour les zones "végétatives" (arboricultures, cultures maraichères et cultures fourragères) avec des valeurs inférieures qui varient entre $\mathbf{0 . 1}$ et $\mathbf{0 . 4}$ (couleur vert, Fig. 6)

- Une deuxième, pour les zones «non végétatives » (friches, labours, grandes cultures sèches...) avec des valeurs inférieures à $\mathbf{0}$ (couleur jaune).

$>$ Classification par règles de décision sur les statistiques de l'indice NDWI (Normalized Difference Water Index) qui permet d'identifier les surfaces ayant une forte teneur en eau et qui renseigne entre autres sur les cultures irriguées. L'indice de la teneur en eau se calcul selon la formule suivante.

NDWI = (PIR-MIR)/ (PIR+MIR) soit, (B5-B7)/ (B5+B7)

(En cas d'images Landsat8/ OLI)

NDWI = (PIR-MIR)/ (PIR+MIR) soit, (B8a-B11)/ (B8a+B11)

(En cas d'images Sentinel/ 2A)

Avec,

PIR : Bande proche infrarouge

MIR : Bande moyen infrarouge

L'indice NDWI, permet d'effectuer un suivi régulier sur l'état hydrique des zones végétatives (Gao, B.-C., 1996). Il varie de "-1" (teneur en eau négatif avec une sécheresse sévère), à "1" (bonne humidité). En effet, la structure interne des feuilles et la matière sèche influencent nettement la réflectance dans la bande PIR. Quant à celle de MIR, elle reflète les changements de la teneur en eau et la structure spongieuse de la mésophile, d'où, une valeur plus faible de la bande MIR et qui reflète une teneur en eau élevée (http://www.quadratic.be). Par ailleurs, la combinaison des deux bandes PIR et MIR soustrait d'éventuelles variations dues à la structure interne des plantes et à la matière sèche. 

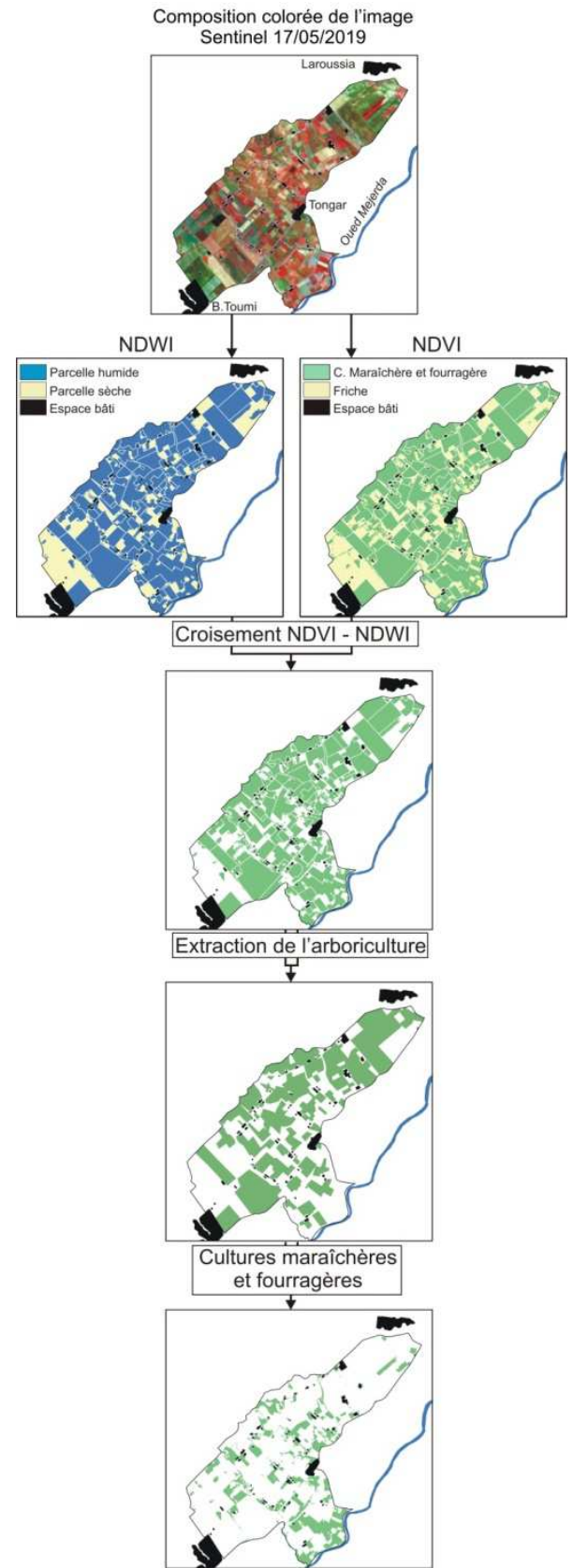

Fig. 5. Calcul des indices NDVI et NDWI et extraction des superficies réservées aux cultures maraîchères et fourragères (exemple appliqué à l'image Sentinel-2 du 17/05/2019) 
L'utilisation de l'indice NDWI en dehors de la saison pluvieuse témoigne fortement sur les exploitations irriguées et/ou sur les champs les plus actifs photosynthétiquement (NDVI élevé). En effet, pendant la saison estivale (essentiellement le mois de juillet) des corrélations fortes peuvent être observées entre l'indice NDWI et NDVI, ceci dit que les parcelles agricoles les plus humides sont celles photo-synthétiquement les plus actives (http://www.quadratic.be). En contrepartie, il faut signaler que pour certains arbustes la réponse photosynthétique est très tardive par rapport à la période d'arrosage, d'où, une corrélation faible entre les indices. Dans ce même contexte et pour certaines cultures, une valeur plus élevée de l'NDVI correspond parfois à un NDWI faible. En réalité, les parcelles agricoles les plus actives (NDVI) assimilent l'eau plus rapidement que celles les moins actifs.

Le calcul de l'NDWI est réalisé également sous le logiciel Arc Gis (raster calculator). Une reclassification (basée sur une reconnaissance automatique par le logiciel) a été opérée aux valeurs de l'NDWI. Ainsi, on a obtenu deux classes raster :

- Une première, pour les parcelles « humides » (couleur bleu, Fig. 5).

- Une deuxième, pour les parcelles « sèches » (couleur jaune).

Afin de mieux discriminer les zones végétatives, éliminer les pixels mal affectés par le logiciel pour la classe "végétative » et la classe « humide", on a croisé ces deux couches raster par l'outil d'analyse d'image «difference» (Fig. 5). Les résultats sont par la suite reconvertis en ficher de forme (vecteur). L'estimation des superficies dédiées aux cultures maraichères et aux celles fourragères est réalisée par la soustraction de la superficie de l'arboriculture (qui reste pratiquement la même entre 2015 et 2019) et obtenue déjà à partir d'un fichier de forme (fichier vecteur) réalisé par le Commissariat Régional de Développement Agricole (CRDA) de la Manouba. Les résultats cartographiques obtenus ont servi pour suivre de près les successions culturales à une échelle intra-annuelle, interannuelle et parcellaire (Fig. 6 et 7).

Beaucoup d'informations ont été également recueillis sur le PPI de Borj Toumi, grâce à une enquête ${ }^{2}$ réalisée en mai et en juillet 2018.

2 L'enquête réalisée fait partie d'une étude qui vise à diagnostiquer, cartographier et construire une typologie pour les périmètres irrigués du bassin versant de Mejerda. 
NOUVELLE PERSPECTIVE POUR LA CARTOGRAPHIE

DE LA DYNAMIQUE RECENTE DES PAYSAGES AGRAIRES: ...

L'enquête concerne une centaine d'agriculteurs et les questionnaires touchent aux pratiques agricoles, à la succession culturale, la source d'eau utilisée ainsi qu'à la technique d'irrigation adoptée.

\section{Résultats et discussions}

\section{1) L'évolution intra-annuelle des cultures maraîchères et fourragères}

L'interprétation visuelle des résultats cartographiques (Fig. 6 et 7), et des statistiques (Fig. 8) relatives aux superficies irriguées, issus des images Sentinel et Landsat nous ont permis de déduire les idées suivantes :

$>$ Le satellite Sentinel-2A: Les superficies dédiées aux cultures maraîchères et fourragères pour le mois de mai (2015-2016) sont estimées à près de 300 hectares (Fig. 6 et 8 ). Une régression de l'ordre de $108.8 \%$, de $87.52 \%$ et de $86.51 \%$ des superficies cultivées entre le mois de mai et de juillet est observée respectivement pour 2015, 2016 et 2019. Cette évolution négative est expliquée en grande partie par le fait que beaucoup de produits agricoles ont été déjà récoltés durant le mois de juin, ainsi que par la question de la gestion d'utilisation des ressources en eau (enquête personnelle).

$>$ Le satellite Landsat 8/OLI : Les superficies occupées par des cultures maraichères et fourragères pour les mêmes périodes (mai-juillet/2015-2016), sont assez inférieures à celles obtenues à partir des images Sentinel (Fig. 7 et 8). Les résultats statistiques issus des images Sentinel et Landsat, relatives au mois de mai 2016, montrent un écart d'estimation qui a atteint près de 80 hectares. Ceci peut-être justifié par la résolution spatiale $(10 \mathrm{~m}$ pour le Sentinel et $15 \mathrm{~m}$ pour Landsat après le pancharping) qui influence le degré de précision des calculs effectués sur les images. 


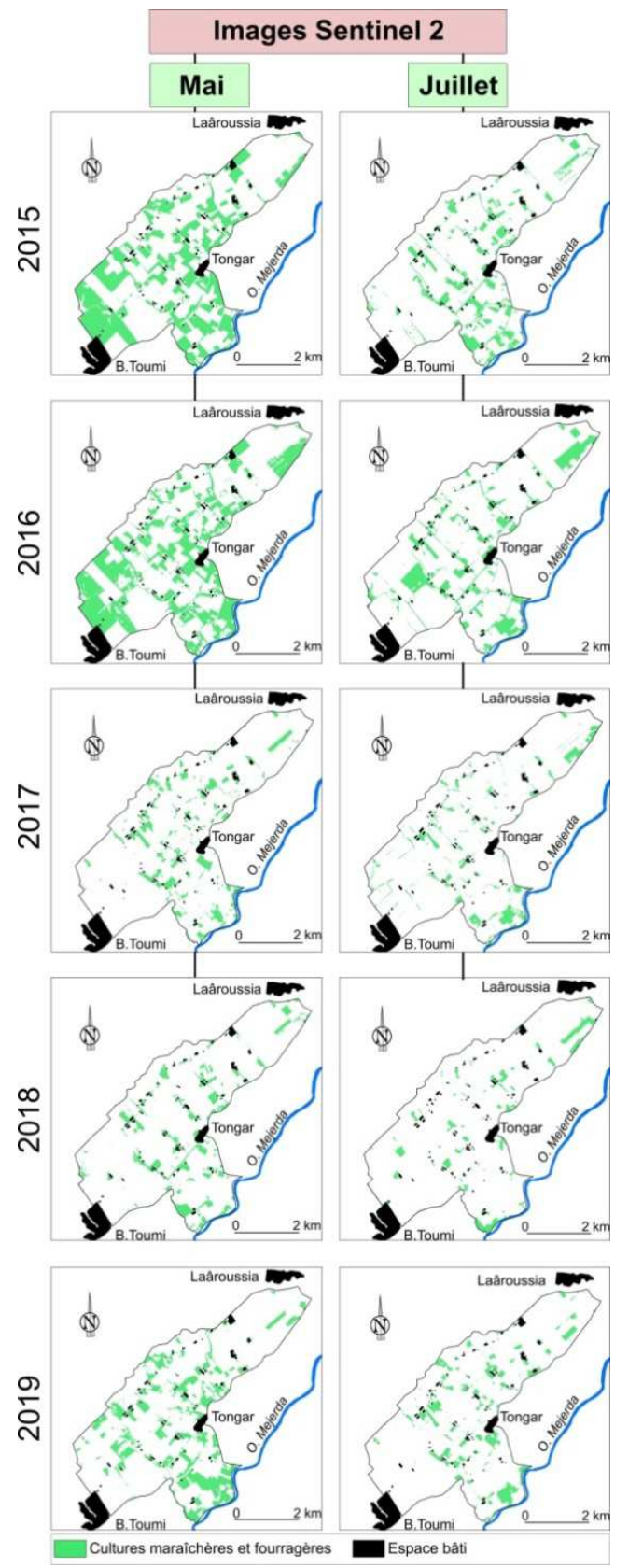

Fig. 6. Répartition spatio-temporelle des cultures maraîchères et fourragères issue des images Sentinel-2 à Borj Toumi entre 2015 et 2019

(la cartographie a été réalisée par le biais d'ArcGis) 


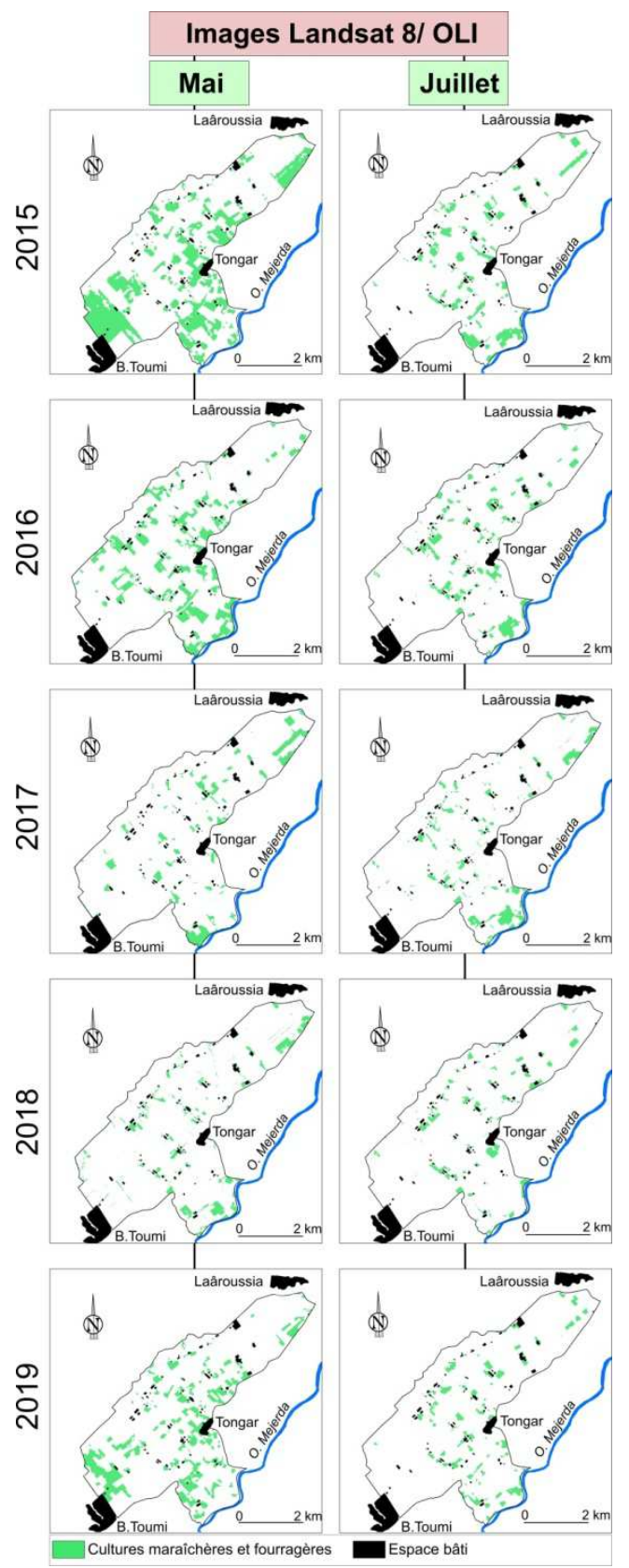

Fig. 7. Répartition spatio-temporelle des cultures maraîchères et fourragères issue des images Landsat/OLI à Borj Toumi entre 2015 et 2019

(la cartographie a été réalisée par le biais d'ArcGis) 
On rajoute que les résultats obtenus à partir des images Sentinel ressemblent beaucoup aux estimations du CRDA de la Manouba (une similitude de près de $88 \%$ ). Les superficies occupées par les cultures irriguées (hors l'arboriculture) sont pratiquement les mêmes pour les mois de mai et de juillet (2017 et 2018) pour les deux satellites.

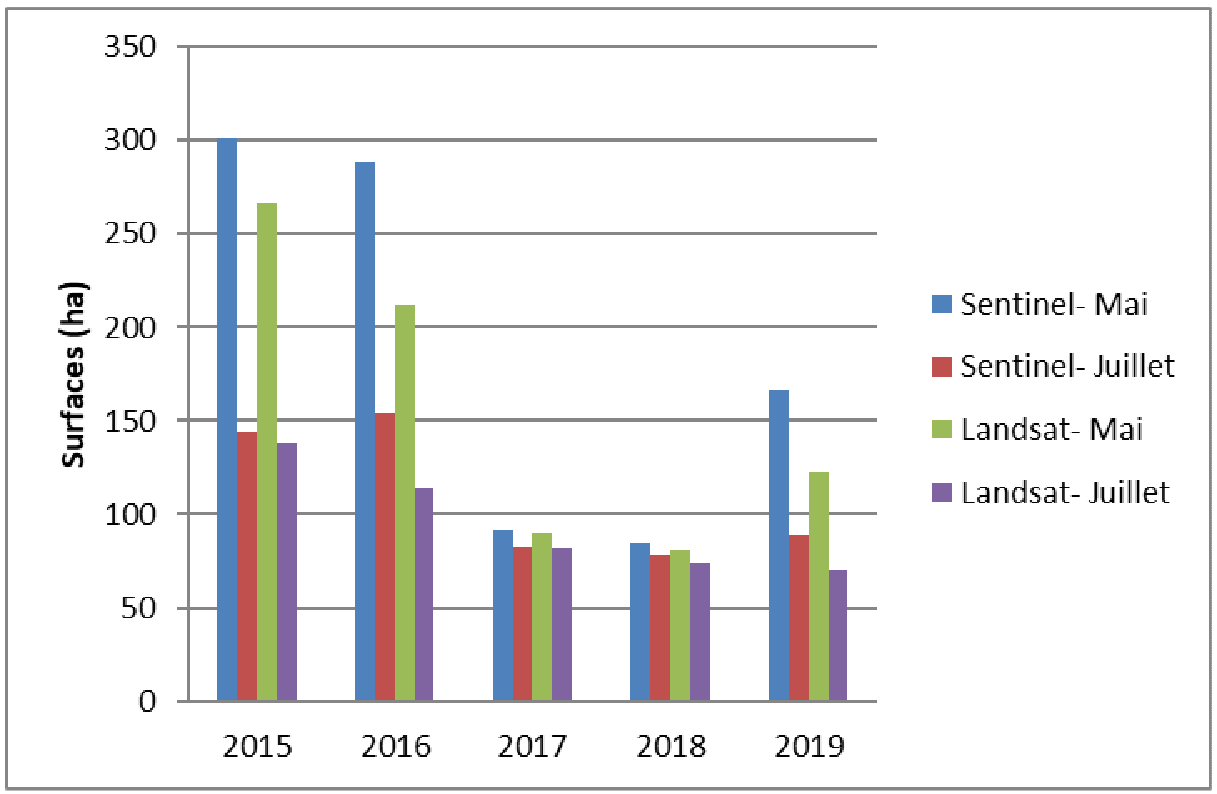

Fig. 8. Evolution des superficies occupées par les cultures maraîchères et fourragères à Borj Toumi entre 2015 et 2019 (calculs effectués via ArcGis)

\section{2) Successions des cultures maraichères et fourragères à l'échelle interannuelle}

A travers les résultats cartographiques et statistiques (Fig. 6, 7 et 8) nous constatons que la superficie des aires exploitées et irriguées par les eaux de Barrage Laroussia en 2017 et 2018 (mai et juillet) ont enregistré une nette régression (dans les images issues des deux satellites) et ce, par rapport aux années précédentes (2015 et 2016). 


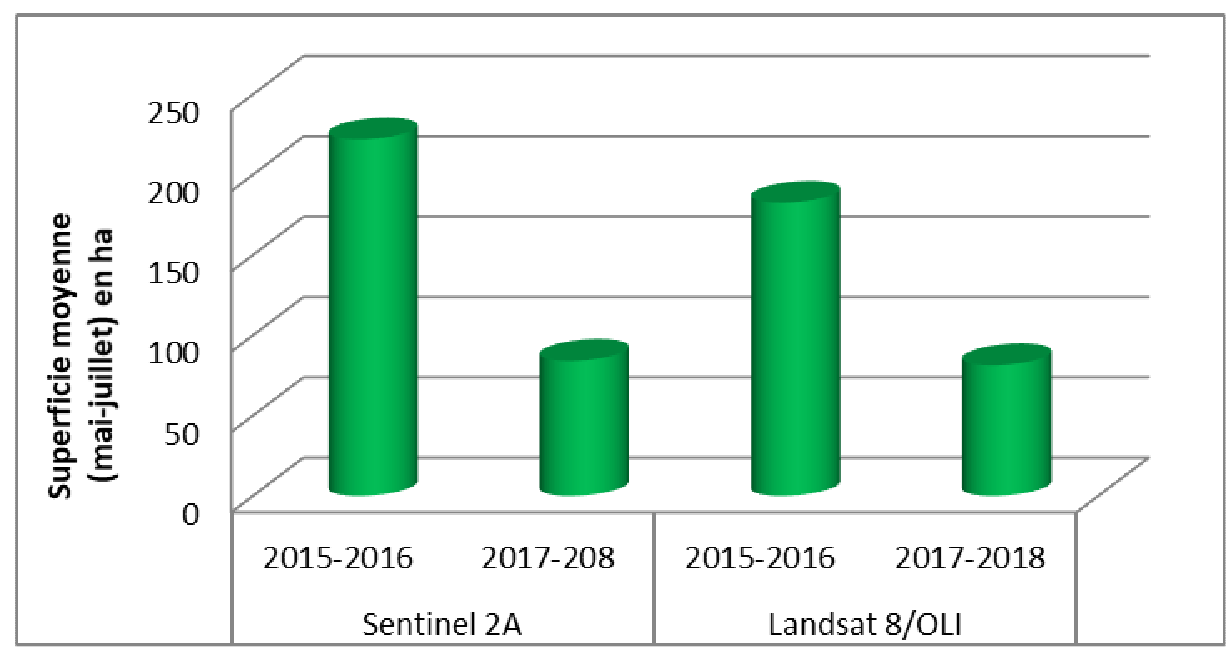

Fig. 9. Evolution des superficies moyennes (mai et juillet) réservées aux cultures maraîchères et fourragères calculées à partir des images Sentinel-2A et Landsat 8-OLI pour la période 2015-2016 et 2017-2018 (calculs effectués par ArcGis)

Le calcul des superficies moyennes (mai et juillet) pour la période 2015-2016 et 2017-2018 (Fig. 9), nous a permis de retenir un taux de régression moyen (des aires réservées aux cultures maraîchères et fourragères) de l'ordre de $163.9 \%$ pour le Sentinel et de $124.42 \%$ pour le satellite Landsat. En revanche, en 2019 et à travers les résultats obtenus par les deux satellites, les superficies irriguées ont enregistré une nette augmentation, notamment, durant le mois de mai (les taux d'évolution ont atteints, $227.68 \%$ pour Sentinel et $114,1 \%$ pour Landsat). Ces grandes fluctuations des pratiques agricoles en irrigué sont en partie expliquées par les apports pluviométriques durant les campagnes agricoles en question. Toutefois, le faible taux d'exploitation (ne dépasse pas $50 \%$ dans les campagnes pluvieuses) et le faible recouvrement des parcellaires agricoles par les maraîchages et par les fourrages témoignent d'une faible utilisation de l'eau d'irrigation. La question qui se pose, s'agit-il vraiment d'un certain boycott en rapport avec la nouvelle conjoncture de la gestion collective de l'eau d'irrigation et ses retombées tarifaires? S'agit-il encore de l'un des conséquences du modèle de gestion jugé défaillant ? Ou bien d'autres facteurs qui sont à l'origine de la faible utilisation de l'eau d'irrigation? 


\section{3) Discussions}

La grande fluctuation des superficies irriguées entre 2015 et 2019 est une conséquence directe de la conjonction de plusieurs facteurs. Les informations recueillies auprès des agriculteurs, des gestionnaires agricoles locales (dans le cadre des études de terrain menées au mois de mai et de juillet 2018) et les rapports officiels du CRDA de la Manouba, nous ont permis de construire une base de données riche et de faire un diagnostic exhaustif pour le périmètre d'étude. Les dynamiques récentes de l'occupation-utilisation des sols à Borj Toumi ainsi que la situation actuelle des exploitations (fonctionnement hydraulique, agronomique et économique) témoignent, sans doute, d'une orientation vers l'arboriculture et les céréalicultures peu exigeantes en eau. Trois facteurs sont à l'origine :

$>$ Une forte dépendance entre les réserves hydriques des barrages et les superficies cultivées en irrigué : Le barrage réservoir de Laâroussia fait partie du grand projet « des eaux du nord » qui se caractérise par des Transferts connectés au réseau. «Les réserves hydriques du barrage Laâroussia dépondent fortement des eaux lâchées du grand barrage de Sidi Salem. Or, les stocks de ce dernier ont connu une baisse remarquable pour la période 2017-2018 par rapport à celle de 2015-2016» (Fig. 10) (Samaâli, H. et Mjejra, M., 2020). Cela est dû principalement à l'irrégularité de la pluviométrie pendant les campagnes agricoles, ainsi, qu'à la répercussion de la période de stress hydrique qui marque la Tunisie ces dernières années (situation liée aux changements globaux). Par conséquent, un nouveau plan de gestion de l'eau d'irrigation a été établi et les CRDAs ont octroyé seulement $20 \%$ des volumes habituelles destinées à l'irrigation pour les saisons agricoles 2017 et 2018 (Samaâli, H. et Mjejra, M., 2020). Cette nouvelle politique hydraulique qui domine sur la gestion de l'eau d'irrigation explique en partie la forte corrélation $\left(R^{2}=0.71\right)^{3}$ observée entre les superficies cultivées (en mai et en juillet),

3 Le coefficient de corrélation $\mathrm{R}^{2}$ est calculé à travers deux paramètres (P1 : superficies occupées par les cultures maraîchères et fourragères ; P2 : stocks en eau disponibles dans le grand barrage de Sidi Salem) pour la période 2015-2019. 
estimées à partir des images Sentinel-2 et les stocks en eau disponibles dans le barrage de Sidi Salem pour la période 2015-2019 (Fig. 10).

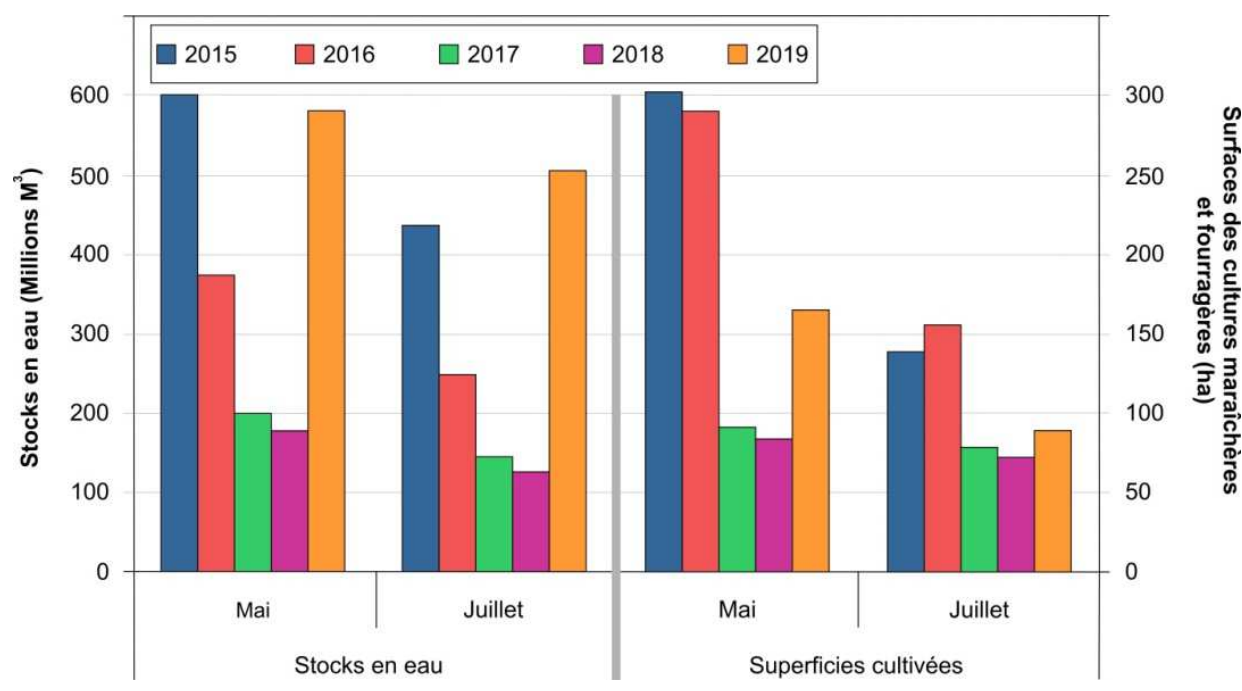

Fig. 10. Forte corrélation entre les stocks en eau disponibles dans le barrage de Sidi Salem et les superficies occupées par des maraîchages et des fourrages dans le PPI de Borj Toumi pour la période 2015-2019 (www.onagri.nat.tn/ et calculs personnels par ArcGis)

$>$ Le dysfonctionnement $d u$ réseau d'irrigation: L'irrigation est assurée principalement par le complexe de pompage "El Herri" (Société d'Exploitation du Canal et des Adductions des Eaux du NordSECADENORD). Le réseau installé depuis plus de 50 ans, constitue une vraie contrainte pour l'opération d'irrigation. D'une part, il est devenu trop vétuste, d'autres parts il n'assure plus les besoins théoriques des cultures consommatrices de l'eau (maraîchages et fourrages) pendant la phase de stress hydrique. En effet, l'extension aménagée dans le nord-est du périmètre a fortement perturbé l'opération d'irrigation et a exercé une pression sur le réseau actuel qui engendre d'importantes fuites dans les conduites encore fonctionnelles (Samaâli, H. et Mjerjra, M., 2020). Dans cette même optique, l'étude faite par Hanafi, S. et al, (2014) a montré que si le réseau d'irrigation fonctionne pendant $12 \mathrm{~h}$ par jour, il n'assure que $1 / 5$ des besoins théoriques des plantes de mai à septembre.

Le réseau d'irrigation de Borj Toumi est conçu pour irriguer près de 1/3 de la superficie agricole utile SAU (OMVVM, 1960) avec un débit 
fictif de l'ordre de $0.43 \mathrm{l} / \mathrm{s}$ ha pour les cultures maraîchères et l'arboriculture dans le secteur gravitaire (techniques d'irrigation de surface). Au niveau des secteurs sous pression, le débit fictif est de $0.6 \mathrm{l} / \mathrm{s}$ ha (Hanafi, S. et al., 2014). L'extension de la superficie du périmètre et la situation actuelle du réseau soulignent des divergences. Le recours vers l'intensification des cultures et les besoins théoriques des spéculations ne concordant pas avec la capacité maximale de l'offre du réseau notamment pendant le mois de juillet. Le réseau actuel ne permet pas d'irriguer que $30 \%$ de la superficie totale (CRDA de la Manouba, 2018). Ce constat, a eu des répercussions sur le choix des cultures, à titre d'exemple l'artichaut (culture marquant le secteur d'étude) est très rarement cultivé dans le PPI de Borj Toumi (enquête personnelle).

Des opérations de maintenance et de rénovation des conduites, (qui sont animées par le CRDA de La Manouba), ont démarré depuis janvier 2020. Ces aménagements visent à :

- Remplacer les petites et les moyennes conduites en amiante ciment détruites par d'autres de type PEHD.

- Effectuer des maintenances pour les supports des conduites superficiels ouverts et éliminer le boccage avoisinant.

- Eliminer les prises d'eau arbitraire installée sur les conduites principales.

- Installer des compteurs.

- Remplacement de 20 canaux principaux (entretien avec le responsable du Groupement de Développement Agricole de Tongar-Al WifaK).

$>$ L'impact de la nouvelle tarification de l'eau d'irrigation: Les entretiens directs menés auprès des agriculteurs dans le cadre d'une enquête personnelle nous ont permis de constater des changements dans les pratiques agricoles à Borj Toumi. En effet, le système de culture a évolué depuis le début des années 1990 vers l'adaptation de l'arboriculture et des grandes cultures peu consommatrices en eau. Ceci est dû aux effets de l'application du PASA «manifesté par une transformation $\mathrm{du}$ cadre institutionnel et une décentralisation des services de l'Etat aux dépens des organisations d'usagers de l'eau » (Samaâli, H. et Mjejra, M., 2020). L'Association d'Intérêt Collectif (AIC) de Tongar, s'est chargée depuis sa création en 1993 de la gestion du 
périmètre. Conformément à la nouvelle conjoncture (l'eau est devenue une ressource rare), une tendance vers l'économie de l'eau règne sur le processus de gestion. La droite d'ajustement du volume d'eau facturé au niveau du périmètre d'étude (Fig. 11), montre une régression nette des stocks utilisés pour l'irrigation depuis 1966. Le phénomène s'est accentué depuis le début des années « 1990 » suite au changement dans le processus de gestion de l'eau d'irrigation accompagné par des modifications de la tarification. Dans cette même optique, $78 \%$ des agriculteurs enquêtés estiment que les tarifs préférentiels appliqués aujourd'hui par le groupement de développement agricole de Tongar-Al Wifak pèsent lourd sur leurs budgets et se sont trouvés obliger de recourir à des spéculations peu exigeantes en eau et à forte valeur ajouté tel que l'arboriculture. Par conséquent, le PPI de Borj Toumi se trouve aujourd'hui dominé par l'arboriculture (58\% de la SAU, Fig. 12), notamment par des oliviers, par plusieurs variétés de pêcher, ainsi que par les poiriers, les pommiers et les manguiers (enquête personnelle). 


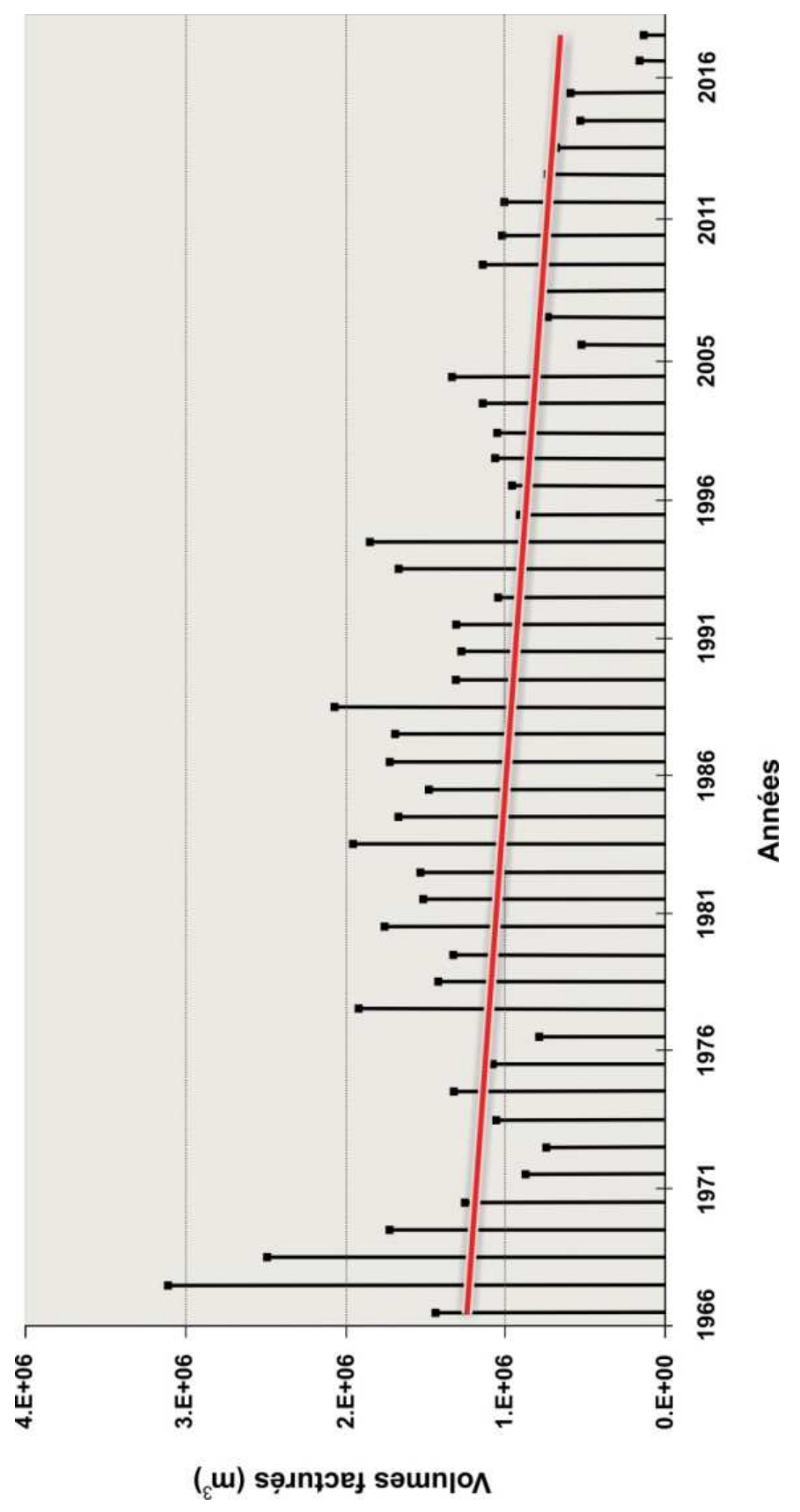

Fig. 11. Evolution du volume d'eau facturé dans le périmètre de Borj Toumi depuis sa mise en eau (Hanafi S., 2011 et Commissariat Régional au Développement Agricole (CRDA) de la Manouba, 2018) 
NOUVELLE PERSPECTIVE POUR LA CARTOGRAPHIE

DE LA DYNAMIQUE RECENTE DES PAYSAGES AGRAIRES: ..
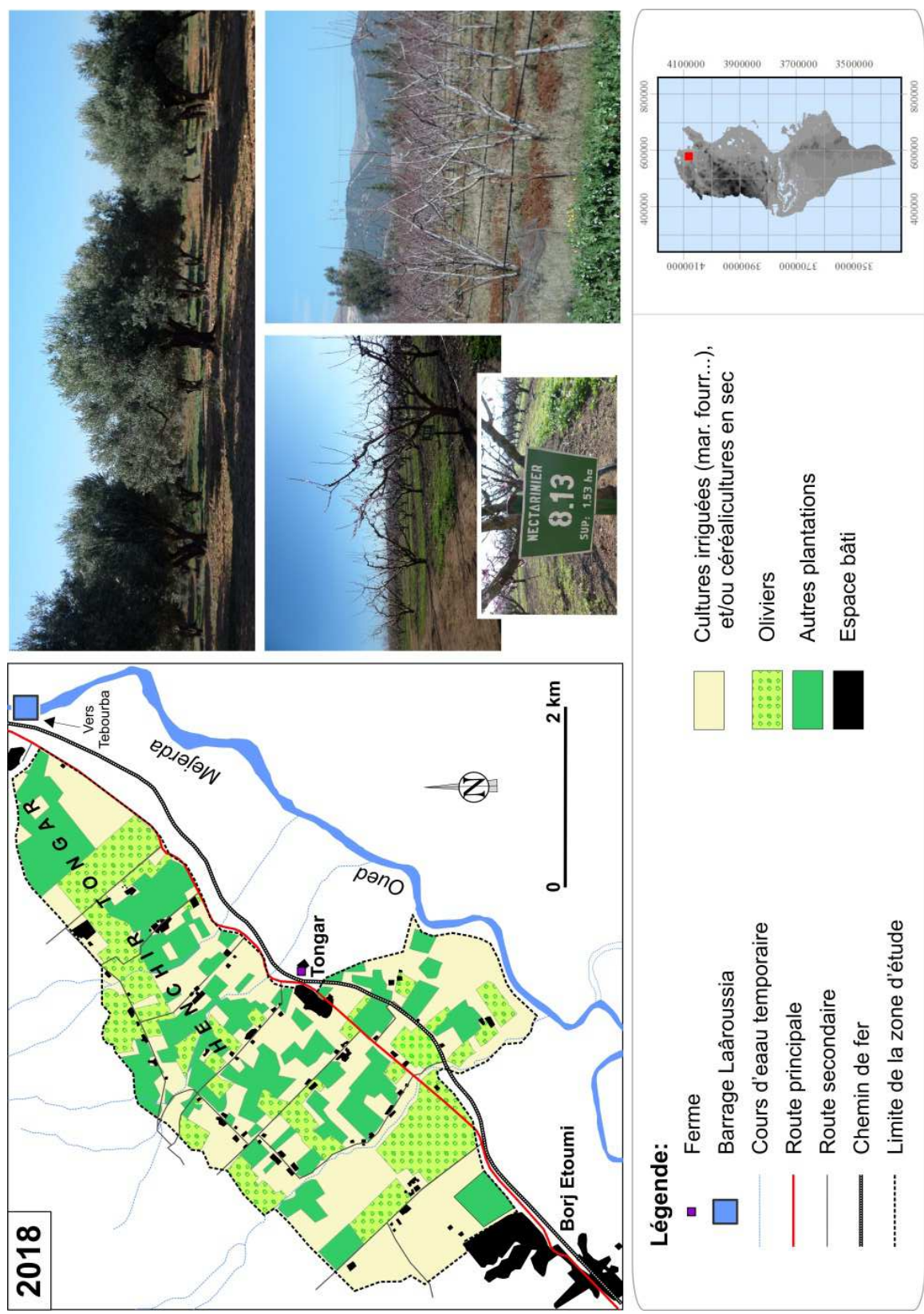

Fig. 12. L'arboriculture domine les spéculations agricoles dans le PPI de Borj Toumi (Cartographie : Samaâli H., 2019 à partir de la carte agricole de Manouba, des orthophotos à l'échelle 1/5000 et des extraits d'images Google Earth 2018; photos auteur, 2020) 


\section{Conclusion}

Le PPI de Borj Toumi constitue un prototype de l'agriculture irriguée dans la basse vallée de Mejerda. L'évolution du système de production dans ce secteur est le résultat d'une rénovation agraire entrepris par l'Etat tunisien au lendemain de l'indépendance. L'objectif est d'assurer le passage d'un modèle défaillant caractérisé par une agriculture d'autosubsistance à un autre performant par le biais de la production en intensif. Ce périmètre est destiné à produire des maraîchages, des céréales, des fourrages et de l'arboriculture. Or plusieurs facteurs ont abouti à une organisation spatiale caractérisée par la dominance de l'arboriculture et des céréales en secs. Les superficies réservées aux cultures maraichères et fourragères sont très diversifiées à l'échelle interannuelle et interannuelle. Ces fluctuations sont dues essentiellement aux variations des apports pluviométriques, à l'augmentation de la demande sur les ressources en eau en rapport avec l'accroissement démographique, l'évolution économique,... les changements institutionnels et l'impact sur la gestion et la tarification de l'eau d'irrigation. Bien évidement $d$ 'autres facteurs influencent considérablement l'utilisation de l'eau pour l'irrigation au PPI de Borj Toumi, notamment le mode d'irrigation pratiqué, l'état du réseau...

L'approche méthodologique utilisée dans cette étude (basée sur l'utilisation des images multi-capteurs) a donné des résultats assez acceptables (forte corrélation entre les superficies des cultures maraîchères et fourragères d'une part et les stocks en eau disponibles au barrage de Sidi Salem). Ceci est dû aux différentes corrections effectuées (notamment radiométriques). En même temps, les images Sentinel 2A et Landsat 8/OLI sélectionnées, ne présentent ni nuages ni brouillard sur toute la zone d'étude. Toutefois, des lacunes résident toujours dans l'utilisation des images optiques, pour cela, un recours à un couplage avec des images Radar nous semble parfois nécessaire afin d'avoir des résultats fiables.

Les résultats présentés dans ce travail constituent, de ce fait, un premier pas vers une meilleure connaissance du système «agriculture irriguée-gestion de l'eau ». Le cadre législatif, institutionnel, organisationnel est fondamental pour comprendre l'évolution du système de production 
en irrigué au sein d'un PPI, mais pas suffisant. L'avenir de l'agriculture irrigué en Tunisie est fortement lié à la révision du modèle de gouvernance défaillant et à l'évaluation des performances de la gestion collective de l'irrigation à travers les associations d'usagers.

\section{BIBLIOGRAPHIE}

Agence Française de Développement (AFD), 2008, Programme sectoriel eau n², 12 p.

Allen, R.G., Pereira, L.S., Raes, D., Smith, M., 1998, Crop evapotranspiration (guidelines for computer crop water requirements), FAO Irrig. and Drain. Paper No. 56, Food and Agricultural Organization of the United Nations, Rome.

Belhedi, A., 2017, L'aménagement de l'espace en Tunisie : la reproduction ou l'alternative ? Publications de la Faculté des Sciences Humaines et Sociales de Tunis, 2 ème édition, 303 p.

Ben Hamouda, N., 1999, Stratégies des agriculteurs irrigants confrontés à une situation de pénurie d'eau : le cas d'un périmètre irrigué privé dans le bassin de Merguellil Tunisie centrale, Thèse de C.I.H.E.A.M., 167 p.

Chennoufi, S., 1981, Les conditions sociologiques du succès d'une réforme agraire: Le cas de la Basse-Vallée de Mejerdah en Tunisie, thèse de doctorat de $3^{\text {ème }}$ cycle, Université de Toulouse - Le Mirail, 278 p.

Commissariat Régional au Développement Agricole (CRDA) de la Manouba, mai 2018, Rapport annuel des activités, $134 \mathrm{p}$.

Excoffier, Y., 1954, Petite histoire de la Tunisie, 2ème édition, LA CARAVELLE, 129 p.

Gao, B.-C., 1996), « NDWI - A normalized difference water index for remote sensing of vegetation liquid water from space », Remote Sensing of Environment n`58, pp. 257-266.

Hanafi, S., 2011, "Approche d'évaluation de la performance des systèmes irrigués à l'échelle des exploitations agricoles: Cas du périmètre irrigué de Borj Toumi (vallée de la Medjerda-Tunisie) ", Agriculture, économie et politique, 92 p., http://.ar chives-ouverts.fr/ tel-00920810

Hanafi, S., Zairi, A., Ruelle, P., Le Grusse, P. et Ajmi, T., 2014, « Typologie des exploitations agricoles : un point de départ pour comprendre les performances des systèmes irrigués », 10 p., http://.archives-ouverts.fr/ tel-00920810)

Hénia, L., (Dir.), 2008, Atlas de l'eau en Tunisie, Unité de recherche GREVACHOT, 186 p.

Jaziri, B., 2020, « Analyse cartographique et paysagère des transformations spatiales du couvert forestier des Mogods (Tunisie septentrionale) », Physio-Géo, Volume 15 | -1, pp. 1-27, http://journals.openedition.org/physio-geo/9956

Lamhamedi, B.E., Jnah, N., Sebari, I. et Benbahria, Z., 2017, « Extraction automatique des zones irriguées dans la région du Gharb par analyse d'image basée-objets des images Landsat 8 », Revue Marocaine des Sci. Agron. Vét. 5 (2), pp. 170-177, https://www.agrimaroc.org/index.php/Actes_IAVH2/article/view/495 
Nasr, J., 2015, Gouvernance et performance de la gestion de l'eau d'irrigation en Tunisie : cas des périmètres irrigués de Nadhour-Zaghouan, Thèse de Doctorat, INAT, Tunis, $229 \mathrm{p}$.

Samaâli, H. et Mjejra, M., 2020, «La réforme agraire et son impact sur le secteur de Borj Toumi (nord-est de la Tunisie) : entre la mutation spatiale et l'émergence d'un modèle de gouvernance territoriale ». Actes du colloque "Aménagement et développement des territoires: entre gouvernance, dynamique économiques et protection de l'environnement", Annaba, novembre 2018 (article accepté).

Samaâli, H., 2016, Cartographie de la dynamique de l'occupation-utilisation du sol, le delta de Mejerda, Publications FSHS de Tunis, 388 p.

Samaâli, H., 2019, «L'eau et l'agriculture irriguée dans le bassin-versant de Mejerda : cartographie de la mobilisation et acteurs de gouvernance », Actes du colloque "Régionalisation et gouvernance", Centre de publication universitaire \& UR: Régionalisation, développement régional et urbain, pp. 201-230.

Toomanian, N., Gieske, A. S.M., Akbary, M., 2004, «Irrigated area determination by NOAA-Landsat upscaling techniques, Zayandeh River Basin, Isfahan, Iran », Int. J. Remote Sens. ${ }^{\circ} 25$, pp. 4945-4960.

Traoré, F., Djaby, B., Wellens, J. et Tychon, B., 2012, «Estimation des zones agricoles irriguées du bassin versant du Kou à l'aide de la télédétection », Publications, Université de Liège, 9 p., https://orbi.uliege.be/handle/2268/132698

Velpuri, N.M., Thenkabail, P.S., Gumma, M.K., Biradar, C., Dheeravath, V., Noojipady, P. et Yuanjie, L., 2009, "Influence of resolution in irrigated area mapping and area estimation », Photogrammetric Engineering and Remote Sensing, n75(12), pp. 1383-1395.

\section{WEBOGRAPHIE}

https://www.usgs.gov/

http://www.quadratic.be

http://www.onagri.nat.tn/

\section{LISTE DES ABREVIATIONS}

AFD : Agence Française de Développement.

AIC : Association d'Intérêt Collectif.

CRDA : Commissariat Régional au Développement Agricole.

GDA : Groupement de Développement Agricole.

INECO : Instruments INstitutionnels et ECOnomiques (pour la gestion durable de l'eau dans la région méditerranéenne).

MIR : (Bande) Moyen InfraRouge.

NDVI : Normalized Difference Vegetation Index.

NDWI : Normalized Difference Water Index.

OLI : Operational Land Imager. 
NOUVELLE PERSPECTIVE POUR LA CARTOGRAPHIE

DE LA DYNAMIQUE RECENTE DES PAYSAGES AGRAIRES: ..

OMVVM : Office de la Mise en Valeur de la Vallée de Mejerda.

PASA : Plan d'Ajustement Structurel Agricole.

PIP : Périmètre Irrigué Privé.

PIR : (Bande) Proche InfraRouge.

PISEAU : Projet d'Investissement dans le Secteur de l'Eau.

PNEEI : Programme National d'Economie d'Eau en Irrigation.

PPI : Périmètre Public Irrigué.

SECADENORD : Société d'Exploitation du Canal et des Adductions des Eaux du Nord.

SIG : Système d'Informations Géographiques

STEG : la Société Tunisienne d'Electricité et du Gaz.

THRS : Très Haute Résolution Spatiale.

UTM : Universal Transverse Mercator. 
